Article

\title{
The Formation of Barite and Celestite through the Replacement of Gypsum
}

\author{
Pablo Forjanes ${ }^{1, *(\mathbb{D})}$, José Manuel Astilleros ${ }^{1,2}$ (D) and Lurdes Fernández-Díaz ${ }^{1,2}$ (D) \\ 1 Departamento de Mineralogía y Petrología, Universidad Complutense de Madrid, 28040 Madrid, Spain; \\ jmastill@ucm.es (J.M.A.); lfdiaz@geo.ucm.es (L.F.-D.) \\ 2 Instituto de Geociencias (IGEO), (UCM, CSIC), Ciudad Universitaria, 28040 Madrid, Spain \\ * Correspondence: pforjane@ucm.es
}

Received: 27 January 2020; Accepted: 17 February 2020; Published: 19 February 2020

check for updates

\begin{abstract}
Barite $\left(\mathrm{BaSO}_{4}\right)$ and celestite $\left(\mathrm{SrSO}_{4}\right)$ are the end-members of a nearly ideal solid solution. Most of the exploitable deposits of celestite occur associated with evaporitic sediments which consist of gypsum $\left(\mathrm{CaSO}_{4} \cdot 2 \mathrm{H}_{2} \mathrm{O}\right)$ or anhydrite $\left(\mathrm{CaSO}_{4}\right)$. Barite, despite having a broader geological distribution is rarely present in these deposits. In this work, we present an experimental study of the interaction between gypsum crystals and aqueous solutions that bear $\mathrm{Sr}$ or Ba. This interaction leads to the development of dissolution-crystallization reactions that result in the pseudomorphic replacement of the gypsum crystals by aggregates of celestite or barite, respectively. The monitoring of both replacement reactions shows that they take place at very different rates. Millimeter-sized gypsum crystals in contact with a $0.5 \mathrm{M} \mathrm{SrCl}_{2}$ solution are completely replaced by celestite aggregates in less than 1 day. In contrast, only a thin barite rim replaces gypsum after seven days of interaction of the latter with a $0.5 \mathrm{M} \mathrm{BaCl}_{2}$ solution. We interpret that this marked difference in the kinetics of the two replacement reactions relates the different orientational relationship that exists between the crystals of the two replacing phases and the gypsum substrate. This influence is further modulated by the specific crystal habit of each secondary phase. Thus, the formation of a thin oriented layer of platy barite crystals effectively armors the gypsum surface and prevents its interaction with the Ba-bearing solution, thereby strongly hindering the progress of the replacement reaction. In contrast, the random orientation of celestite crystals with respect to gypsum guarantees that a significant volume of porosity contained in the celestite layer is interconnected, facilitating the continuous communication between the gypsum surface and the fluid phase and guaranteeing the progress of the gypsum-by-celestite replacement.
\end{abstract}

Keywords: gypsum; barite; celestite; dissolution-precipitation; mineral replacement

\section{Introduction}

Barite $\left(\mathrm{BaSO}_{4}\right)$ and celestite $\left(\mathrm{SrSO}_{4}\right)$ are the end-members of a nearly ideal solid solution. Despite its thermodynamics characteristics, this solid solution series shows a marked compositional bimodality $[1,2]$ and samples with compositions that strongly differ from those of the two end-members are very rarely found in nature [3]. Celestite $\left(\mathrm{SrSO}_{4}\right)$ is relatively common in a large diversity of sedimentary and igneous settings, where often appears scattered in small pockets [4,5]. Large deposits of celestite are rare and most of those that concentrate million metric tons appear associated with coastal marine carbonate and evaporite sequences [6]. These exploitable deposits of celestite are thought to have formed during diagenesis due to the interaction of Sr-bearing aqueous solutions with sedimentary beds of calcium sulfate minerals, namely gypsum $\left(\mathrm{CaSO}_{4} \cdot 2 \mathrm{H}_{2} \mathrm{O}\right)$ and/or anhydrite $\left(\mathrm{CaSO}_{4}\right)$ [6]. This interaction would be the starting point for a dissolution-crystallization reaction. Thus, the sulfate released to the fluid phase upon dissolution of gypsum and/or anhydrite would react 
with the dissolved strontium and lead to the precipitation of celestite. Indeed, celestite pseudomorphs after gypsum microcrystals and cm-sized selenite crystals are abundant in the large celestite deposits of Granada (Spain) or Coahulia (Mexico), which gives support to the interpretation that relates the origin of these deposits to the development of interface coupled dissolution-precipitation (ICDP) reactions [7]. Barite $\left(\mathrm{BaSO}_{4}\right)$ has a much broader geological distribution than celestite ([3] and references therein). Most barite deposits form through the mixing of sulfate-rich fluids, such as seawater, with fluids charged with Ba after their interaction with silicate minerals [3]. Although barite can also form after gypsum and/or anhydrite [4,8], barite deposits associated to sulfate evaporite sequences are volumetrically much less relevant than their celestite counterparts [5,6].

ICDP reactions play a major role in the re-equilibration between mineral phases and aqueous fluids in the Earth's crust. Evidences of the development of these reactions are found in a plethora of geological settings, including sedimentary, diagenetic, metamorphic, and metasomatic environments [9,10]. ICDP reactions initiate with the formation of nuclei of a secondary phase on the surface of a primary one. These reactions then proceed through the inwards advance of a sharp reaction front located at the interface between a progressively thicker rim of the secondary phase and a shrinking core of the primary one. This inwards advance of the reaction front can only take place if communication between the fluid phase and the reaction front is continuously maintained. In those ICDP reactions that involve a negative molar volume change this communication is guaranteed by a network of interconnected porosity that develops concomitantly to the formation of the secondary phase [11]. This porosity balances the volume reduction associated to the reaction and thereby allows the preservation of the external shape of the primary phase $[9,12-14]$. This explains that most ICDP reactions are pseudomorphic $[9,12-14]$. The volume of porosity generated during ICDP reactions is not exclusively defined by the difference in molar volume between the phases involved. A further porosity contribution arises when the secondary phase is less soluble than the primary one [14-16]. Finally, factors like the solid to fluid volume ratio [17], the evolution of the composition of the fluid at the reaction front [18], the existence/absence of crystallographic relationships between the phases involved in the ICDP reaction [19], the presence of pre-existing cracks or other defects within the primary phase crystals [20] as well as the specific morphological and textural features of the secondary phase [21-26] can also contribute to modulate the volume of porosity generated during ICDP reactions and, more importantly, to define the spatial arrangement of the ICDP reaction-related porosity within the secondary phase [27-29]. The permeability and tortuosity of the thus-generated porosity network effectively define the degree of communication between the fluid phase and the reaction front. It has, as a result, a strong impact in the kinetics of the ICDP reactions.

In this work, we present an experimental study of the interaction of gypsum fragments with Ba and Sr-bearing solutions. Since barite and celestite have smaller molar volumes and solubilities than those of gypsum, it can be expected that this interaction will result in the pseudomorphic replacement of the gypsum crystals by the former phases through the development of ICDP reactions. By comparing the characteristics of these two mineral replacement processes, we aim to better understand how the kinetics of ICDP reactions is influenced by intrinsic (differences in molar volume, solubility, crystallographic similarities between the involved phases) and extrinsic (composition of the fluid phase) factors.

\section{Materials and Methods}

Replacement experiments were carried out by placing optically clear gypsum single crystals (Teruel, Spain) into closed polypropylene vessels filled with $1.5 \mathrm{~mL}$ of $0.5 \mathrm{M}$ Sr or Ba-bearing aqueous solutions. The gypsum fragments were cleaved along $\{010\}$, the most common crystallographic form in the habit of gypsum [30], to obtain freshly cleaved $2 \mathrm{~mm}$ thick, square-shaped $\left(5 \times 5 \mathrm{~mm}^{2}\right)$ slices. X-ray fluorescence spectroscopy (XRF) and X-ray diffraction (XRD) analysis confirmed the starting material as highly pure gypsum. The $\mathrm{Sr}$ and Ba-bearing aqueous solutions were prepared by dissolving reagent-grade $\mathrm{SrCl}_{2} \cdot 6 \mathrm{H}_{2} \mathrm{O}$ and $\mathrm{BaCl}_{2} \cdot 2 \mathrm{H}_{2} \mathrm{O}$ (Sigma Aldrich, St. Louis, MO, USA) in high purity 
deionized water (MiliQ; Burlington, MA, USA) (18 M $2 \cdot \mathrm{cm})$, respectively. The gypsum slices were recovered from the solution after interaction times ranging from $5 \mathrm{~min}$ to $168 \mathrm{~h}$ (one week). In all cases, partially to completely replaced crystals were washed first with water and then with ethanol, rapidly dried by blowing pressurized air on their surfaces and left to further dry overnight at $45^{\circ} \mathrm{C}$ in a thermostatic chamber. All experiments were carried out at $25 \pm 0.5^{\circ} \mathrm{C}$ and atmospheric pressure. Each run was repeated at least three times to quantify the variability of the measurements.

The reacted samples were crushed using an agate mortar and analyzed with powder X-ray diffraction $(X R D)$ for phase composition evaluation. The diffractometer was a microprocessor-controlled PANalytical X'Pert PRO MRD, $\mathrm{Cu}-\mathrm{K} \alpha$ radiation and a scan recording in the $2 \theta$ angle range between $5^{\circ}$ and $50^{\circ}$. Standard mineral files of the Crystallographic Open Database (COD, 2017 version) and diffraction diagrams were correlated to determine solid phases. A semiquantitative estimation of the percentage of each mineral phase was derived applying the reference intensity ratio (RIR) method [31] and using the X'Pert High Score Plus software from PANalytical while considering the RIR values included in the PDF cards COD96-901-3165 for gypsum, COD96-900-0651, for barite and COD 96-900-4484 for celestite. The spatial group considered for both barite and celestite was Pnma. Reacted gypsum crystals, both whole and cross-cut perpendicular to their (010) surface were then mounted on holders and coated, first with carbon and then with gold. Some of the cross-cut sections were also prepared by embedding the reacted samples in epoxy resin and dry-polishing them down to the middle. The usage of water during polishing was avoided to prevent gypsum dissolution. Both types of samples were studied using a scanning electron microscope (SEM) (JEOL JSM 6400, Akishima, Tokyo, Japan; $40 \mathrm{kV}$ ) equipped with an energy dispersive spectrometer (EDX; LINK Ex1; Oxford Instruments $80 \mathrm{~mm}^{2} \mathrm{X}$-Max SDD) to obtain information on dissolution features on the primary surfaces as well as on the chemical and morphological characteristics of newly-formed precipitates. Furthermore, the advancement of the replacement reaction front was followed by observing contrast differences in electron backscattered (BSE) images of the cross-cut samples.

\section{Results}

\subsection{Gypsum Interaction with a Sr-Bearing Aqueous Solution}

XRD diffraction patterns corresponding to gypsum crystals interacted with a $0.5 \mathrm{M}$ Sr-bearing solution during progressively longer times are depicted in Figure 1a. All peaks in those diffraction patterns can be assigned to either gypsum (Gp) or celestite (Clt) with no evidence of the formation of any other phase at any intermediate stage of the interaction. Celestite readily forms soon after the interaction starts, as evidenced by the presence of peaks corresponding to this phase in the diffractogram of the gypsum sample interacted with the Sr-bearing solution as short a time as $5 \mathrm{~min}$. Furthermore, the results of XRD semi-quantitative analyses reveal that the gypsum-to-celestite transformation advances rapidly (Figure 1b). Thus, after $6 \mathrm{~h}$ of interaction the celestite content of the reacted gypsum sample is above $99 \mathrm{wt} \%$. After $24 \mathrm{~h}$ the reacted sample exclusively consists of celestite.

The rapid kinetics of the gypsum-to-celestite transformation upon interaction with a Sr-bearing solution is further confirmed by the results of SEM imagining. Figure 2a depicts a SEM micrograph of a gypsum (010) surface after $10 \mathrm{~min}$ of interaction. As can be seen, this surface already shows a significant coverage by celestite crystals, which appear randomly oriented with respect to the gypsum substrate. A complete carpeting of the gypsum substrate by celestite crystals is achieved after $30 \mathrm{~min}$ of interaction with the Sr-bearing solution (Figure $2 b$ ). The increase in the degree of coverage of the gypsum substrate by celestite crystals is accompanied by significant morphological changes in the latter, whose habit evolves from bone folder-like crystals, firstly, to sheaf-like aggregates (Figure 2c) and to spherulites (Figure 2d) latter on. EDX analyses confirm that these celestite crystals have Ca contents in the range between $0.6 \mathrm{wt} \%$ and $1.2 \mathrm{wt} \%$ regardless of their morphology. 


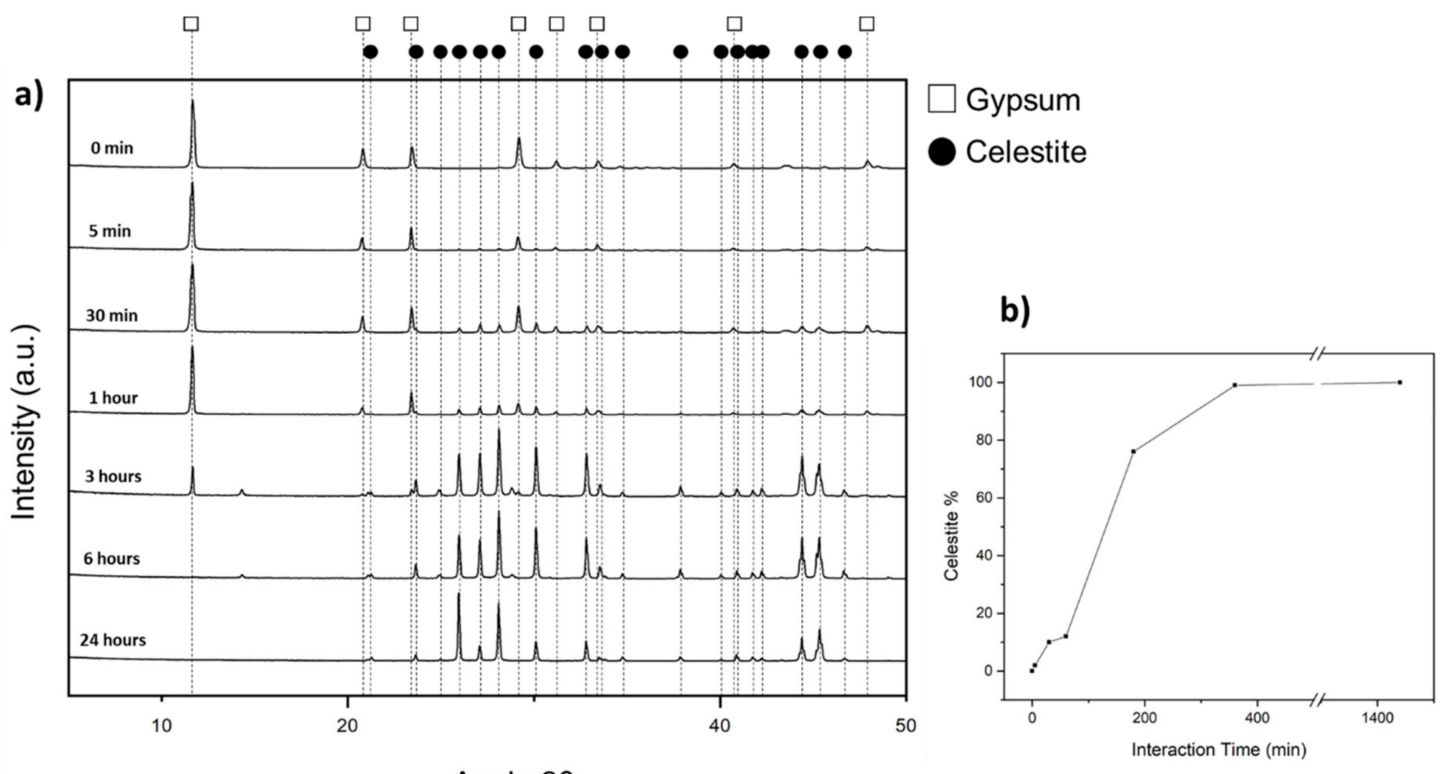

Angle $2 \theta$

Figure 1. (a) X-ray diffraction patterns of gypsum crystals after different times of interaction with a 0.5 M Sr-bearing aqueous solution. The X-ray diffraction patterns show that gypsum grains are almost fully transformed into celestite after $6 \mathrm{~h}$. After $24 \mathrm{~h}$ the transformation is complete. (b) Newly formed celestite content of the gypsum interacted samples, calculated from RIR analyses of XRD data, plotted against interaction time.

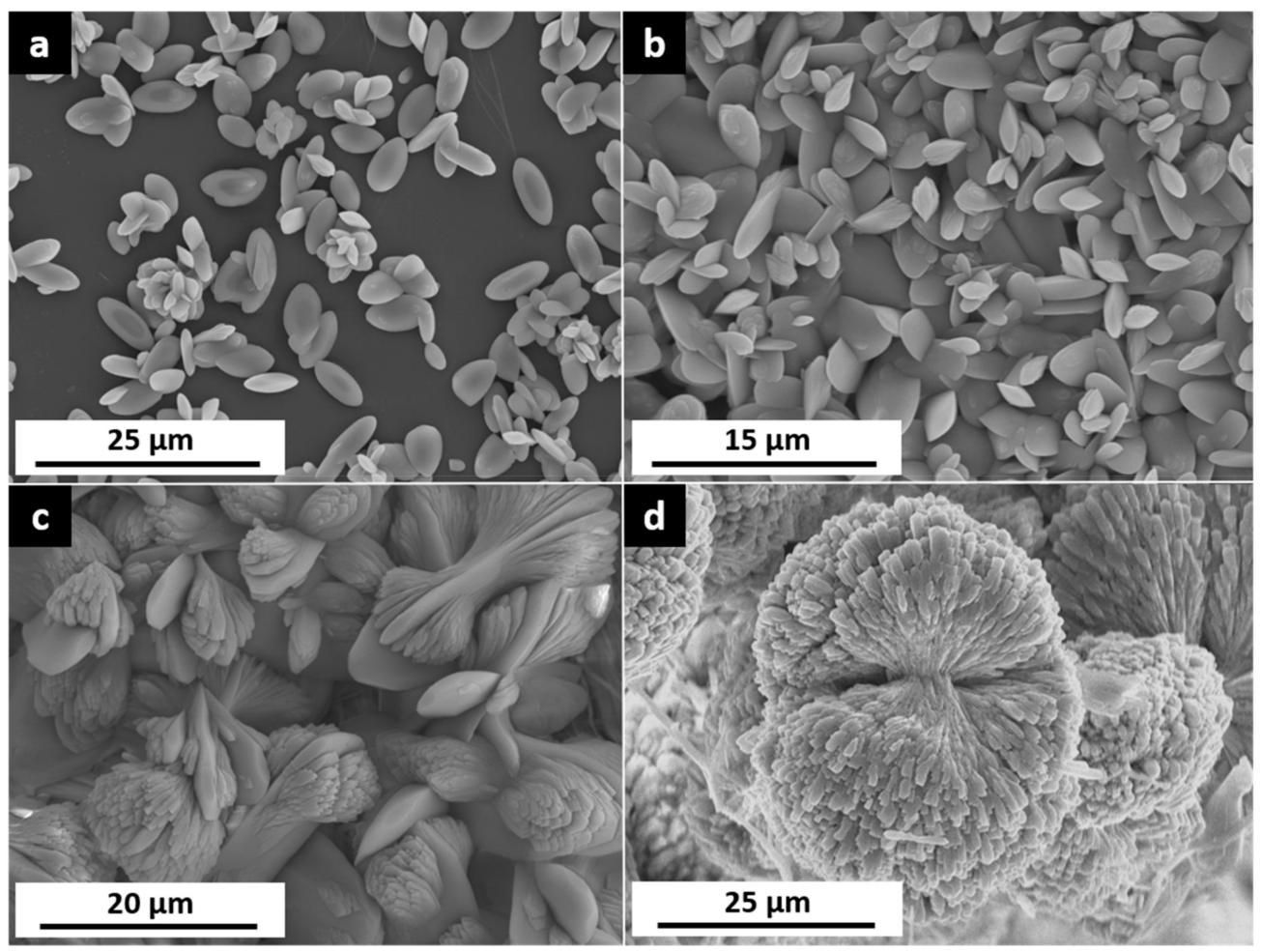

Figure 2. (a) SEM micrographs of micrometer-sized celestite crystals formed on a gypsum (010) surface after $10 \mathrm{~min}$ interaction with a $0.5 \mathrm{M}$ Sr-bearing aqueous solution. Celestite crystals are initially bone folder-shaped. (b) After 30 min of interaction the whole (010) gypsum surface appears carpeted with celestite crystals. (c,d) With increasing elapsing time, celestite crystals gradually evolve from single crystals to crystal aggregates that are either (c) sheaf-life shaped (interaction time $=3 \mathrm{~h}$ ) or even (d) spherulitic (interaction time $=1$ day). 
The external shape of the gypsum crystals is preserved along the whole transformation process, which leads to the formation of celestite pseudomorphs after gypsum. The SEM micrograph in Figure 3a clearly depicts a shell-like rim of celestite that surrounds a relict unreacted core in a partially transformed gypsum sample. SEM imagining of cross-cut sections shows that the contact between this rim and the gypsum core is sharp and marks the reaction front (Figure $3 \mathrm{~b}$ ). As the interaction with the Sr-bearing solution progresses, the reaction front moves inwards, leading to the progressive thickening of the celestite rim and the concomitant shrinking of the gypsum core. The thickness of the celestite rim is $20 \mu \mathrm{m}$ after $30 \mathrm{~min}$ of interaction and grows to reach $75 \mu \mathrm{m}$ after $3 \mathrm{~h}$. The celestite rim is structured in two regions: A very thin $(<10 \mu \mathrm{m})$ layer of fine grained $(\sim 5 \mu \mathrm{m})$ celestite crystals, located in the most outer part of the pseudomorph, and an inner region that consists of columnar celestite crystals arranged with their length perpendicular to the surface of the pseudomorph, defining a stockade-like structure (Figure 3c).

The thickness of the outer region remains constant during the whole duration of the interaction while the width of the inner one increases with time. This widening is accompanied by a progressive loss of parallelism between the celestite crystals that constitute the stockade-like structure as well as the development of a gap that separates the celestite rim from the shrinking gypsum core (Figure 3b). This gap is already $2 \mu \mathrm{m}$ wide after $30 \mathrm{~min}$ of interaction between the gypsum crystal and the $0.5 \mathrm{M}$ Sr-bearing solution and reaches a $15 \mu \mathrm{m}$ width after an interaction of $3 \mathrm{~h}$.

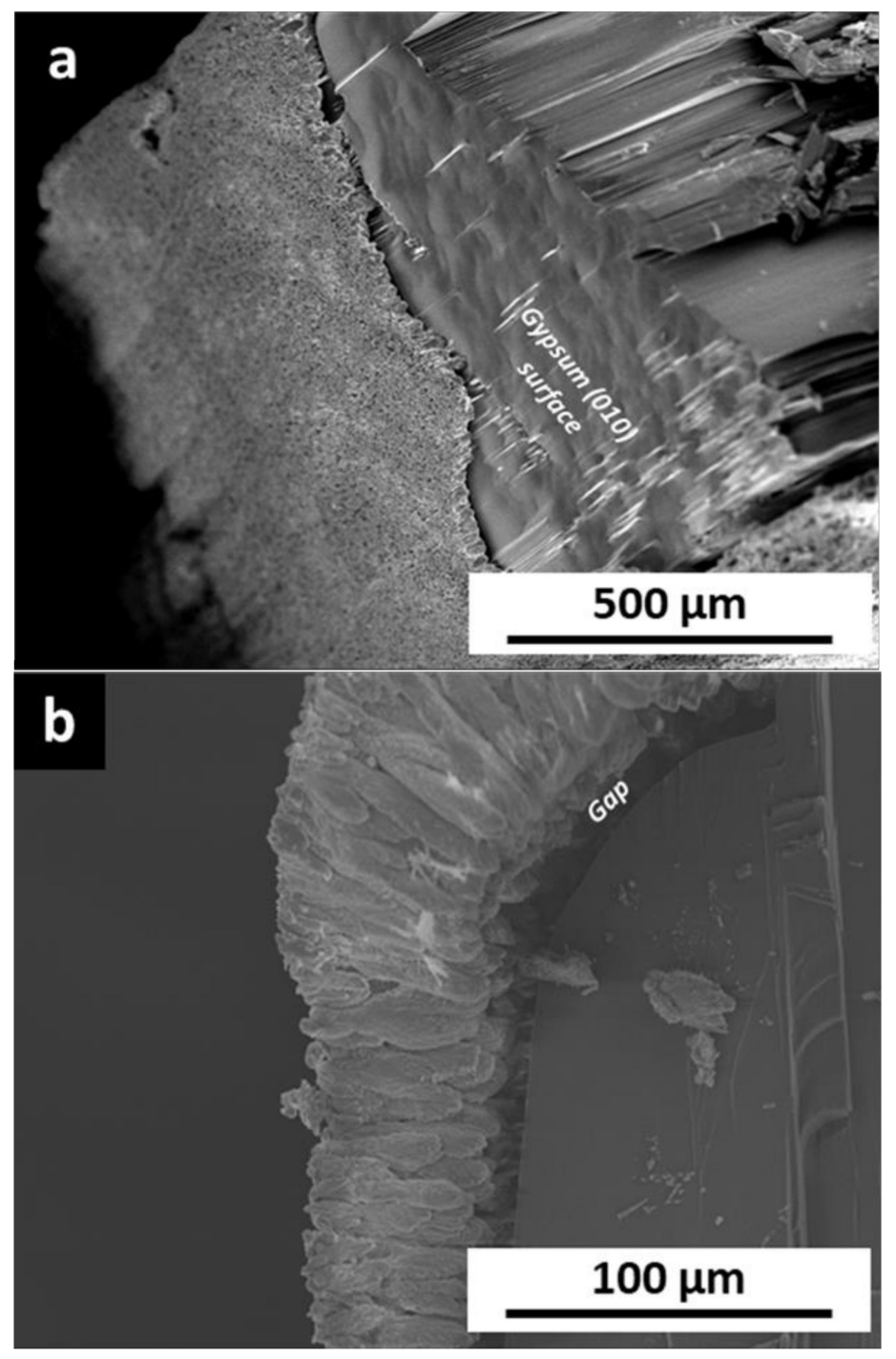

Figure 3. Cont. 


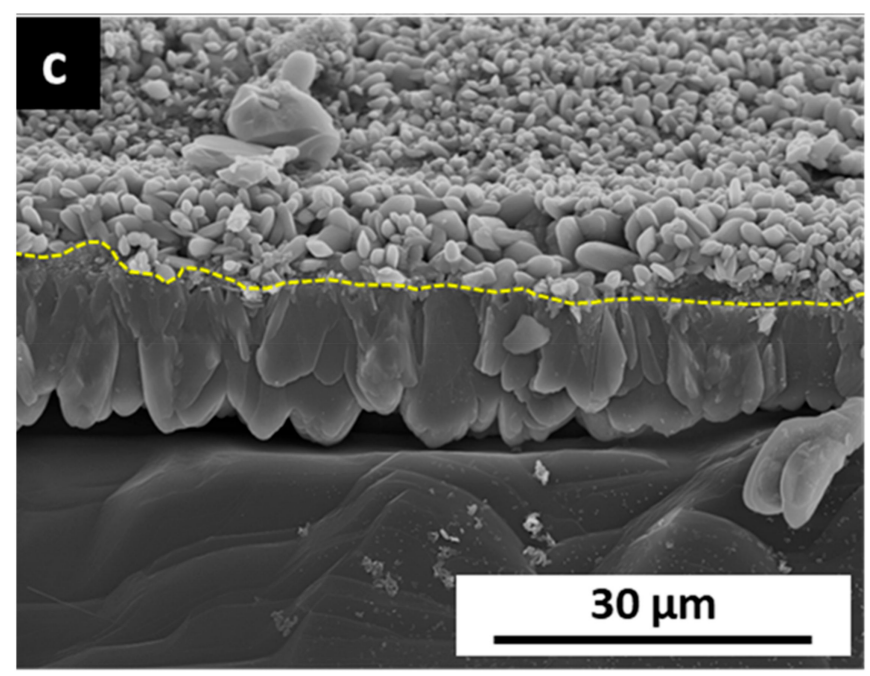

Figure 3. SEM micrographs showing the characteristics of the transformed celestite layer. (a) A shell-rim of celestite crystals encapsulates a gypsum crystal that has interacted $1 \mathrm{~h}$ with a $0.5 \mathrm{M}$ Sr-bearing aqueous solution. (b) Cross cut section image that shows the sharp contact between the unreacted gypsum core and the celestite rim (Interaction time $=3 \mathrm{~h}$ ). A progressive wider gap develops at the contact between the celestite layer and the gypsum core as the interaction time increases. (c) Cross-cut section image that depicts the two regions that can be distinguished within the celestite layer after an interaction time of $30 \mathrm{~min}$. The most outer region is fine grained celestite while the most inner one consists of crystals arranged with their longest axis perpendicular to the retreating surface of the gypsum crystal, defining a stockade-like structure.

Figure 4 shows an epoxy embedded cross section of a partially replaced gypsum crystal cut perpendicularly to (010). The celestite shell-like layer and the gap that separates it from the unreacted gypsum core are clearly visible. It is worthwhile to note that the celestite layer appears significantly thinner perpendicularly to the original (010) surface of the gypsum crystal than perpendicularly to surfaces in the [010] zone. This difference in width is accompanied by differences in the characteristics of the stockade-like structure of the celestite layer. Those crystals that are arranged perpendicularly to surfaces belonging to the [010] zone show much larger length/width ratios and leave larger hollow spaces between them than those arranged perpendicularly to the original (010) surface, which appear as closely packed short prisms. These two crystal arrangement patterns meet close to the corners of the pseudomorph. The stockade-like structure in this region is mainly defined by elongated crystals that are parallel to each other and oriented approximately perpendicular to the gypsum [010] direction, appearing increasingly tilted with respect to this direction the closer to the corners of the pseudomorph they are. The regularity of the stockade arrangement in this region is further disrupted by the presence of a smaller number of short prism-like crystals oriented with its length parallel to the gypsum [010] direction. It is also worthwhile to note that the gap that separates the celestite layer from the gypsum core is wider where the celestite layer is thicker. 


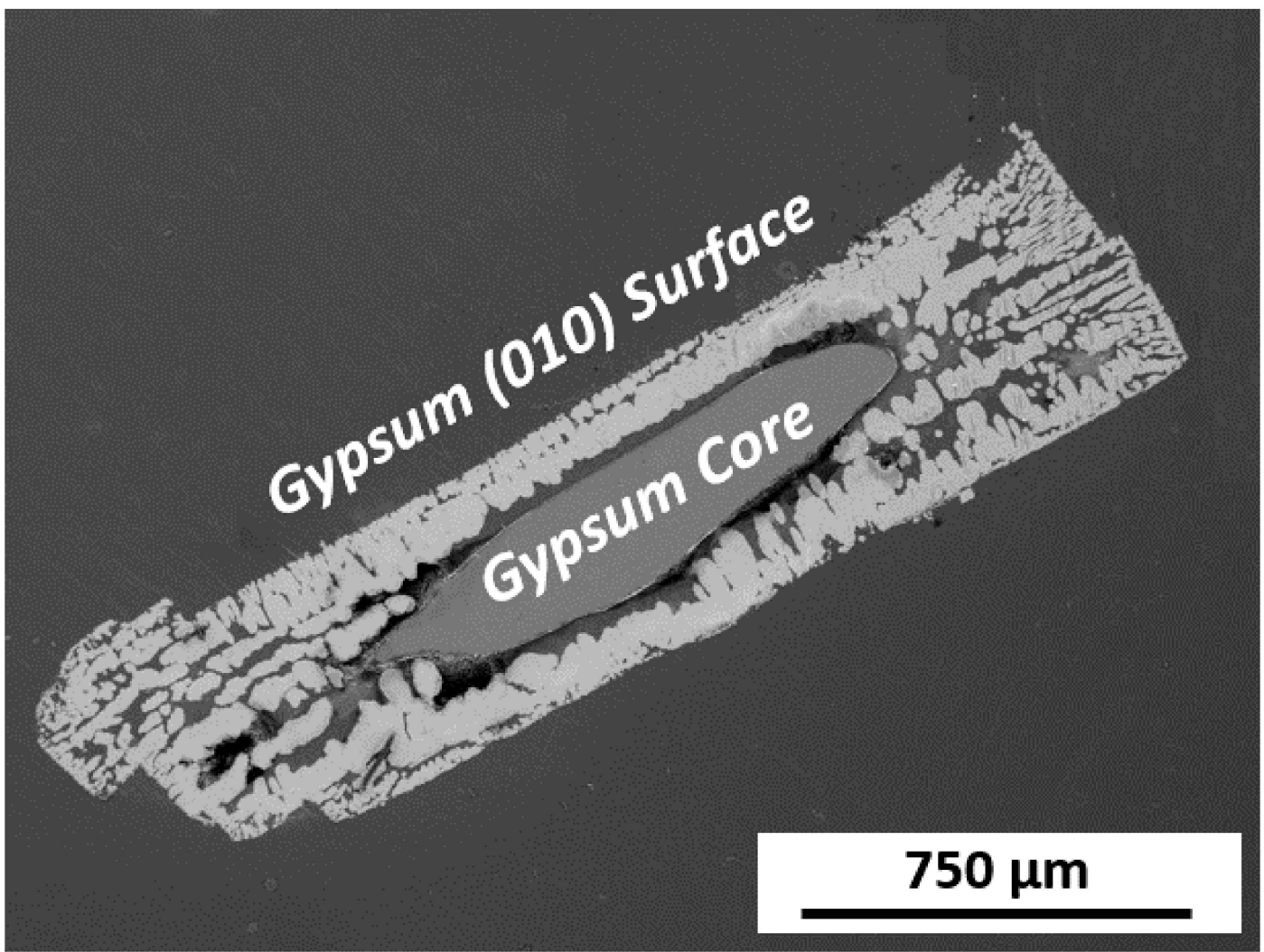

Figure 4. BSE image of a cross-section perpendicular to the (010) surface of gypsum after $3 \mathrm{~h}$ interaction with a $0.5 \mathrm{M}$ Sr-bearing aqueous solution. The width of the celestite secondary layer is not homogeneous. Those regions of the celestite layer that are perpendicular to the gypsum (010) surface reach smaller widths than those perpendicular to surfaces that belong to the [010] zone.

SEM images of cross-sections of fully transformed celestite after gypsum pseudomorphs, epoxy-embedded and cut parallel to the original gypsum (010) surface, are depicted in Figure 5. These SEM images evidence that the progress of the gypsum-to-celestite transformation leads to the development of four distinctly textured celestite regions. These regions are clearly visible in Figure 5a, where yellow dotted lines highlight the boundaries between them. The region located closest to the external surface of the pseudomorph (Region 1) corresponds to the fine grained celestite described above. Immediately beside it, the previously described stockade-like structure appears (Region 2). Moving further closer to the core of the pseudomorph, there is a region defined by spherulitic celestite aggregates (Region 3). This region is around $1.5 \mathrm{~mm}$ wide and occupies most of the celestite pseudomorph. Celestite spherulites in this region are slightly graded in size, with the smaller sized ones ( $20 \mu \mathrm{m}$ in diameter) located closer to the boundary with the stockade-like structured region, while those that are located farer from it reach diameters around 40-50 $\mu \mathrm{m}$ (Figure $5 \mathrm{~b}$ ). These spherulites appear arranged leaving hollow spaces between them, defining a network of interconnected porosity. Finally, the region that corresponds to the core of the pseudomorph (Region 4) consists of elongated prismatic crystals (Figure 5c) that are less closely packed than spherulites in Region 3 and appear sparsely distributed within large volumes of porosity. It is worthwhile to note that the celestite crystals that constitute Region 4 have Ca-contents that are below the detection limit $(<0.1 \mathrm{wt} \% \mathrm{Ca})$, while celestite crystals in the rest of the regions have Ca-contents between 0.6 and $1.2 \mathrm{wt} \%$, according to their EDX analyses. 


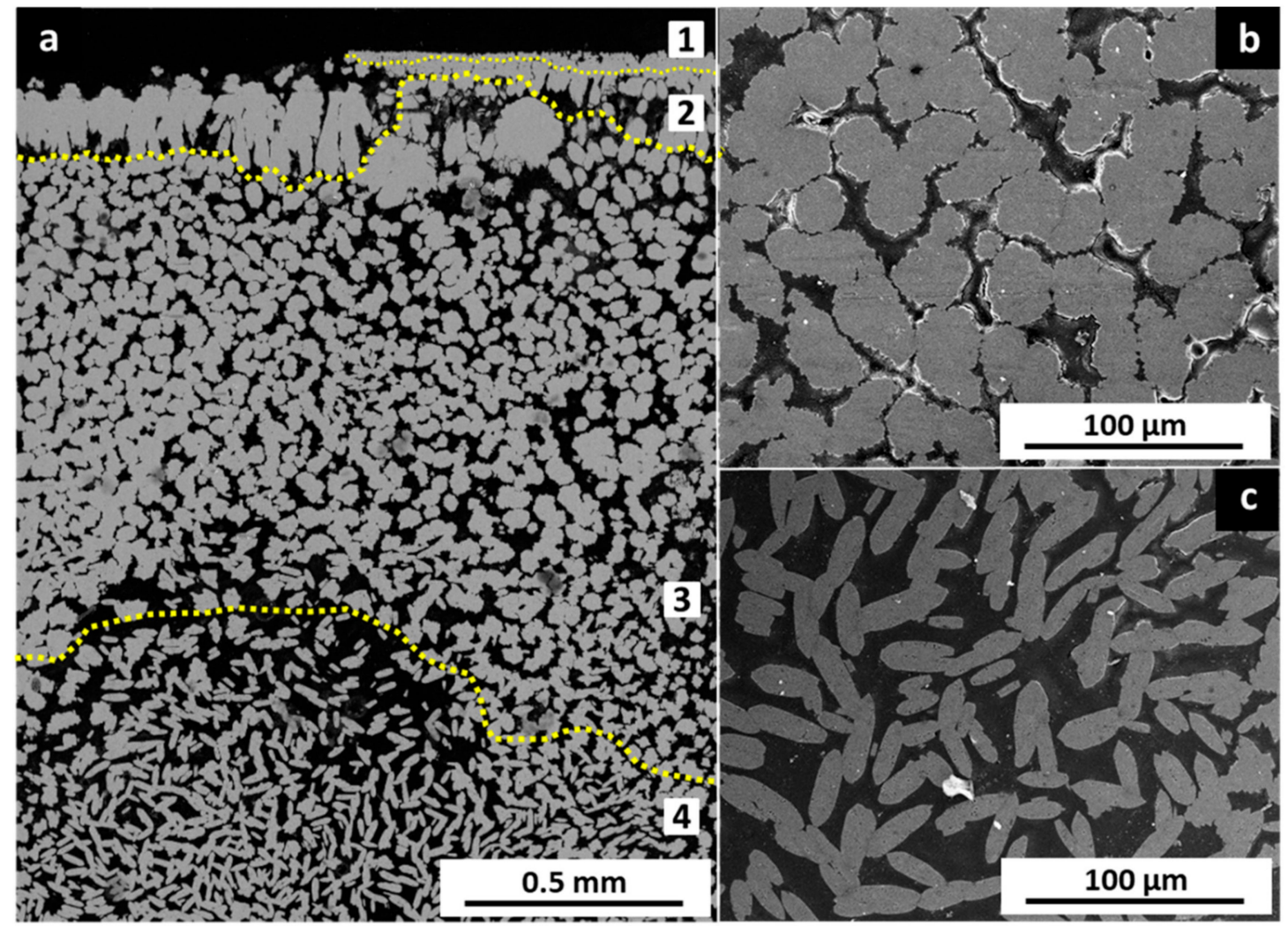

Figure 5. (a) The celestite layer can be divided in four regions. Fine grained celestite crystals constitute Region 1, which is located in the most outer part of the pseudomorph. Moving inwards, the region that appears closest to Region 1 consists of celestite elongated crystals in a stockade-like layer arrangement (Region 2). This is followed by a highly porous region defined by spherulitic aggregates (Region 3). Finally, the most inner region of the pseudomorph is even more highly porous and is built up of sparsely distributed prismatic crystals that leave large hollow spaces between them (Region 4). (b) The spherulitic crystals that constitute Region 3 are gradated in size, with the smallest ones located closer to the boundary with Region 2 and the largest ones appearing closer to Region 4 . These crystals have Ca contents that are similar to those found in the celestite crystals that build up Regions 1 and 2.

(c) The prismatic crystals that constitute Region 4 have a prismatic habit and contain no $\mathrm{Ca}$, according to their EDX analyses.

\subsection{Gypsum Interaction with a Ba-Bearing Aqueous Solution}

XRD diffraction patterns corresponding to gypsum crystals interacted with a $0.5 \mathrm{M}$ Ba-bearing solution during progressively longer times are depicted in Figure 6. All peaks in the diffractograms that correspond to interaction times below $30 \mathrm{~min}$ can be assigned to gypsum. Although the diffractogram corresponding to $30 \mathrm{~min}$ of interaction shows some peaks that can be attributed to barite (Brt), these are very weak and the semi-quantitative analysis indicates that this phase amounts less than $2 \mathrm{wt} \%$. The relative intensity of peaks assigned to barite in diffractograms corresponding to longer interactions barely increases, indicating that gypsum hardly transforms into barite upon interaction with Ba-bearing solutions. Indeed, the semiquantitative analysis of the gypsum sample that interacted with the Ba-bearing solution during 7 days only yields $5 \mathrm{wt} \%$ of barite content.

The sluggish kinetics of the gypsum-to-barite transformation upon interaction with Ba-bearing solutions is further confirmed by the results of SEM imagining. Figure 7 depicts SEM micrographs of gypsum (010) surfaces after (a) $30 \mathrm{~min}$ and (b) $3 \mathrm{~h}$ of interaction, respectively. As can be seen, the gypsum surface is fully carpeted by barite crystals. These crystals are micrometer sized and show a platy habit, which is defined by flat faces, most probably belonging to the $\{001\}$ pinacoid, bounded by curved edges. 


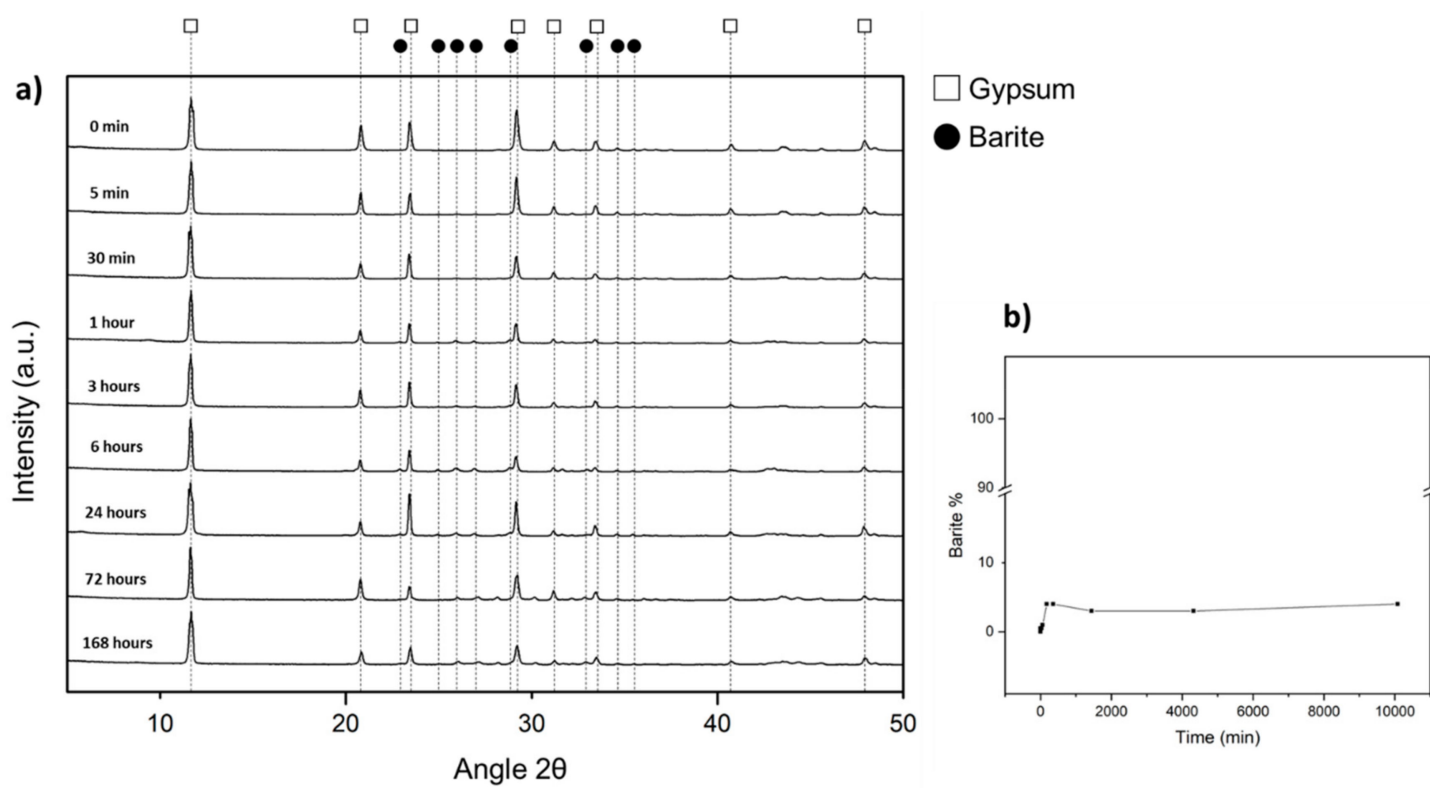

Figure 6. X-ray diffraction patterns of gypsum crystals after different times of interaction with a 0.5 M Ba-bearing aqueous solution. (a) Diffraction peaks corresponding to barite are absent in the diffractograms of gypsum samples interacted with the $0.5 \mathrm{M}$ Ba-bearing aqueous solution during less than $30 \mathrm{~min}$ and are scarce and very weak in the diffractograms of all the samples that interacted longer times, indicating that gypsum barely transforms into barite regardless of the length of the interaction. After one week of interaction, the barite content of the gypsum sample barely amounts for $5 \mathrm{wt} \%$ (b) Newly formed barite content of the gypsum interacted samples, calculated from RIR analyses of XRD data, plotted against the interaction time.

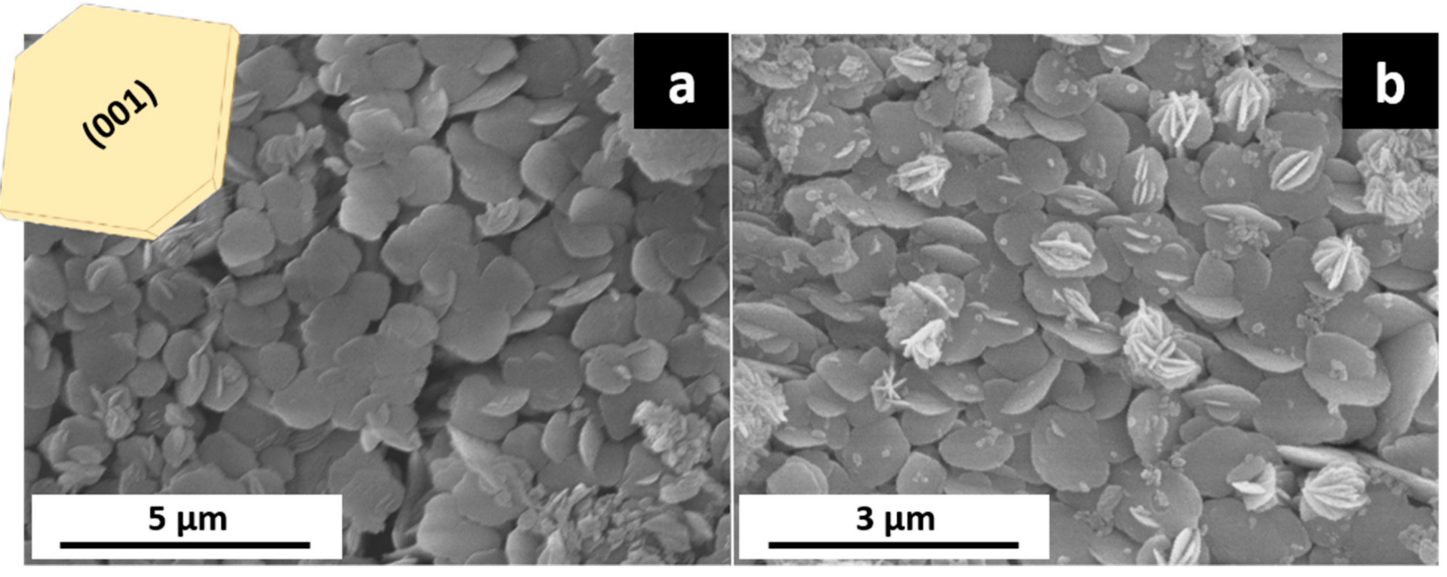

Figure 7. (a) SEM micrograph showing the formation of a micrometer-sized layer of barite that surrounds a gypsum crystal after $30 \mathrm{~min}$ interaction with a $0.5 \mathrm{M}$ Ba-bearing aqueous solution. The habit of barite crystals is dominated by flat faces that belong to the $\{001\}$ form and curved edges perpendicular to the [001] direction. These crystals grow with their (001) faces parallel to the gypsum (010) substrate and are nearly pure in composition according to EDX analyses. (b) As the interaction progresses barite appears as desert-rose-like crystals aggregates rather than as single crystals.

Most barite crystals in Figure 7 lay with their flat faces approximately parallel to the gypsum (010) substrate, although a definite orientation with this substrate appears unclear. Contrarily to the celestite crystals, whose morphology dramatically changes as the interaction of gypsum with a $0.5 \mathrm{M}$ Sr-bearing aqueous solution progresses, barite crystals remain platy-shaped at all times whether they appear as single crystals or as constituents of desert-rose like aggregates (Figure $7 \mathrm{~b}$ ). However, the number of latter progressively increases with the interaction elapsing time (Figure 7b). EDX analyses indicate 
that both, barite single crystals and aggregates are highly pure, with Ca contents below the detection limit $(<0.1 w t \%)$.

SEM images of cross-sections of gypsum crystals cut perpendicularly to their (010) surface after undergoing $\mathrm{a} 3 \mathrm{~h}$ and 7 days interaction with a $0.5 \mathrm{M}$ Ba-bearing solution are shown in Figure 8a,b, respectively. Regardless of the interaction time, gypsum crystals appear encased by a very thin $(<30 \mu \mathrm{m})$ shell-like layer of barite crystals. The small thickness of the barite layer is consistent with the very low barite $\mathrm{w} \mathrm{t} \%$ content of the gypsum reacted samples as estimated from XRD measurements.

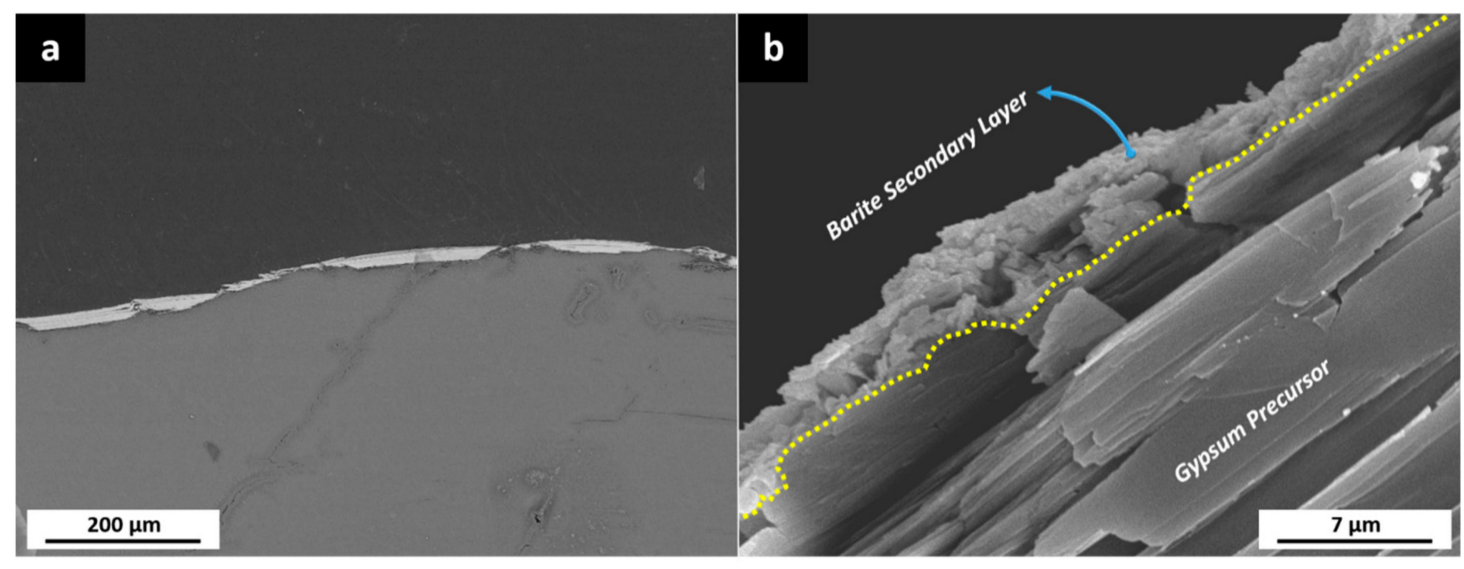

Figure 8. (a) BSE image of a cross section cut perpendicular to the gypsum (010) surface after $3 \mathrm{~h}$ interaction showing the transformed layer. (b) After seven days of interaction the width of the replaced layer does not increase.

\section{Discussion}

Upon interaction with $\mathrm{Sr}$ and Ba-bearing aqueous solutions, gypsum crystals transform into celestite and barite, respectively. In both cases, the transformation initiates at the surface of the gypsum crystal and advances inwards, defining a sharp reaction front that separates a polycrystalline transformed layer from the remaining unreacted core of gypsum. Furthermore, the original external shape of the gypsum crystal is preserved throughout the transformation process. These transformation features are consistent with the transformation taking place through an ICDP reaction. The development of these type of reactions involves the definition of a dissolution-crystallization feedback loop [9,12]. This loop guarantees the coupling through the interface of the rates of the primary phase dissolution and the secondary phase precipitation. In the cases of the transformation of gypsum into celestite and into barite, this feedback loop arises as, upon interaction with the aqueous solution, gypsum starts to dissolve and releases $\mathrm{SO}_{4}{ }^{2-}$ and $\mathrm{Ca}^{2+}$ ions to the liquid phase. The aqueous solution then becomes supersaturated with respect to celestite, if it bears $\mathrm{Sr}^{2+}$, or barite, if it bears $\mathrm{Ba}^{2+}$, which eventually leads to the precipitation of these phases. The depletion of the aqueous solution in $\mathrm{SO}_{4}{ }^{2-}$ that results from this precipitation in turn further promotes the dissolution of gypsum and, consequently, the release of $\mathrm{SO}_{4}{ }^{2-}$ and $\mathrm{Ca}^{2+}$ ions to the liquid phase, thereby feeding the dissolution-crystallization loop. This loop should effectively operate until the complete replacement of the gypsum grains by celestite (or barite) provided that throughout the whole process the concentrations of dissolved $\mathrm{Sr}^{2+}\left(\mathrm{or} \mathrm{Ba}^{2+}\right)$ ions at the gypsum-celestite (or barite) interface are high enough to allow the precipitation of celestite (or barite) through reaction with the released to the liquid $\mathrm{SO}_{4}{ }^{2-}$ ions. Our results show that, indeed, this is the case when a gypsum crystal reacts with an aqueous solution that bears $0.5 \mathrm{M} \mathrm{Sr}$. We observe that in less than $24 \mathrm{~h}$ this interaction results in the pseudomorphic replacement of the whole gypsum crystal by an aggregate of celestite crystals. In contrast, when the gypsum crystal interacts with a $0.5 \mathrm{M}$ Ba-bearing aqueous solution, the gypsum dissolution-barite precipitation loop only works efficiently during a very short time, leading to the formation of a less than $30 \mu \mathrm{m}$ thick layer of barite crystals that surrounds an unreacted gypsum core during the first hour of the interaction. Afterwards, no further advance of the gypsum into barite transformation is observed. 
As explained in the introduction section, the starting point of an ICDP reaction is the nucleation of the secondary phase on the surface of the primary one. Henceforth, for the reaction to progress the continuous communication between the primary phase-secondary phase interface and the bulk solution is required [16]. This communication is guaranteed by the generation of porosity concomitantly to the progress of the transformation when the ICDP reaction involves a negative molar volume change $[9,12]$. More porosity can be added when the ICDP reaction also involves a secondary phase that is less soluble than the primary one [14-16]. Both criteria for the generation of porosity are fulfilled in the cases of the pseudomorphic replacement of gypsum by celestite and by barite. Indeed, both celestite and barite have molar volumes that are smaller than the molar volume of gypsum $\left(\mathrm{V}_{\mathrm{Clt}}=46.25 \mathrm{~cm}^{3} / \mathrm{mol}, \mathrm{V}_{\mathrm{Brt}}=52.11 \mathrm{~cm}^{3} / \mathrm{mol}, \mathrm{V}_{\mathrm{Gp}}=74.31 \mathrm{~cm}^{3} / \mathrm{mol}\right)$. Similarly, celestite and barite are less soluble than gypsum $\left(\mathrm{K}_{\mathrm{spClt}}=10^{-6.63} ; \mathrm{K}_{\mathrm{spBrt}}=10^{-9.97} ; \mathrm{K}_{\mathrm{spGp}}=10^{-4.58} ;\right.$ PHREEQC database $)$. Consequently, at any time during the pseudomorphic replacement of gypsum by celestite or barite the transformed layer that surrounds the unreacted gypsum core contains a volume of porosity that is equal (higher if the solubility-related contribution is taken into account) to the volume loss derived from the molar volume change associated to the replacement reaction $\left(\Delta V=-27.06 \mathrm{~cm}^{3} / \mathrm{mol}\right.$ and $-22.20 \mathrm{~cm}^{3} / \mathrm{mol}$ for the transformation into celestite and barite, respectively): i.e., $\geq 36.4 \%$ porosity when gypsum transforms into celestite and $\geq 30.3 \%$ porosity when it transforms into barite.

The large volume of porosity generated during the transformation of gypsum into celestite facilitates the continuous communication between the gypsum-celestite interface and the bulk solution along the replacement process, explaining the rapid kinetics of the ICDP reaction responsible for this replacement process. This communication is facilitated by the spatial arrangement of this porosity, which appears structured within celestite pseudomorphs from surface to core: (i) in open spaces between randomly oriented celestite crystals, in Region 1, (ii) in channels between approximately parallel elongated celestite crystals, in Region 2, and finally (iii) in large open spaces between celestite spherulitic aggregates, in Region 3, and randomly oriented elongated celestite crystals, in Region 4 (Figure 5). This organization results in a network of interconnected pores that facilitates the transfer of $\mathrm{Sr}^{2+}$ ions from the bulk solution to the interface, where they react with the $\mathrm{SO}_{4}{ }^{2-}$ ions released during gypsum dissolution to precipitate secondary celestite.

The specific features of porosity organization within celestite pseudomorphs after gypsum are the consequence of the combined influence of two factors: (i) celestite crystals nucleate randomly oriented on gypsum surface at the very early stages of the replacement process, and (ii) the release of $\mathrm{SO}_{4}{ }^{2-}$ ions during gypsum dissolution is accompanied by the release of an equal amount of $\mathrm{Ca}^{2+}$ ions and double amount of water molecules. The first factor determines the textural organization of Region 1 in celestite pseudomorphs after gypsum. Furthermore, this factor is also in the origin of the textural organization of Region 2, whose stockade-like structure (Figure 3a,d; Figure 4a,c) develops as differently oriented celestite crystals in Region 1 compete for space during growth. Celestite growth is faster along [001] direction. Those crystals in Region 1 that are oriented so that their [001] direction is perpendicular to the original gypsum surface are in advantage and can grow without interference. In contrast, the development of those crystals differently oriented will be prevented by the lack of space. This competitive growth mechanism rapidly leads to the formation of the parallel column-like celestite crystals that constitute Region 2 of celestite pseudomorphs after gypsum. Competitive growth is a common phenomenon during mineral replacement processes that can significantly influence the texture of the resulting pseudomorph when the secondary phase has a preferential growth direction. Obviously, the randomly oriented nucleation of the secondary phase on the surface of the primary one is a prerequisite for the occurrence of competitive growth phenomena. Stockade-like structures that have been attributed to competitive growth have been described in pseudomorphs of calcite after gypsum [27] and metallic gold after calaverite $\left(\mathrm{AuTe}_{2}\right)$ [32]. In both cases, the early nucleation of the secondary phase on the surface of the primary one was randomly oriented. The transition from parallel column-like celestite crystals in Region 2 to isolated spherulitic aggregates in Region 3 in celestite pseudomorphs after gypsum can be the consequence of the progressive development of a gap 
between the transformed layer and the unreacted gypsum core. This gap, which is clearly visible in Figures 3 and 4, forms due to the difficulty to accommodate within the stockade-like structure the porosity volume required to balance the very large molar volume change associated to the gypsum into celestite transformation. The formation of similar gaps has been observed in other mineral replacement processes involving large negative molar volume changes, like the replacements of gypsum by calcite [27] and pyrochlore by rutile/anatase [33]. The composition of the aqueous solution that fills this gap will evolve as the gypsum into celestite transformation progresses. The concentration of $\mathrm{Sr}^{2+}$ in this solution will be the result from the balance between the amount of $\mathrm{Sr}^{2+}$ transferred from the bulk solution and that consumed through the precipitation of celestite. This concentration will decrease as the transformation progresses. The diluting effect derived from gypsum dissolution, which together to $\mathrm{SO}_{4}{ }^{2-}$ and $\mathrm{Ca}^{2+}$ ions also releases water molecules to the aqueous solution that fills the gap, will further contribute to reduce $\mathrm{Sr}^{2+}$ concentration. Simultaneously, the $\mathrm{Ca}^{2+} / \mathrm{Sr}^{2+}$ concentration ratio will increase. The growth of celestite in a progressively Ca-richer environment could result in the incorporation of a small amount of $\mathrm{Ca}^{2+}$ substituting $\mathrm{Sr}^{2+}$ into celestite structure. This incorporation is consistent with EDX analyses of spherulites, sheaf like and column-like celestite crystals. Since the ionic radii of these cations (ratio Ca ${ }^{\mathrm{XII}}=1.34$; ratio $\mathrm{Sr}^{\mathrm{XII}}=1.44 \AA$ ) is significantly different, this incorporation would introduce lattice strain into celestite structure. This strain could then be released through the formation of dislocations. The distribution of these dislocations in regularly spaced arrays in small angle grain boundaries can explain the progressive loss of parallelism between column-like celestite crystals in Region 2 the farer they are from the surface of the celestite pseudomorph. As the $\mathrm{Ca}^{2+} / \mathrm{Sr}^{2+}$ concentration ratio in the interface solutions continuous to grow due to both, $\mathrm{Sr}^{2+}$ consumption through celestite growth and $\mathrm{Ca}^{2+}$ release through gypsum dissolution, the growth of column-like celestite crystals can become inhibited. Celestite crystallization will then only resume after the supersaturation required for the formation of new celestite nuclei is overcome thanks to the transfer of $\mathrm{Sr}^{2+}$ ions from the bulk solution to the interface. Since these nuclei grow in a $\mathrm{Ca}^{2+}$-rich environment, it is to be expected that they incorporate small amounts of Ca. Sánchez-Pastor et al. [34] demonstrated that celestite crystal habit is very sensitive to isomorphic substitutions. Again, the relaxation of $\mathrm{Ca}$ incorporation-related lattice strain through the formation of dislocations can explain that these nuclei grow to form the sheaf-like and spherulitic celestite aggregates that constitute the Region 3 of celestite pseudomorphs. EDX analysis of these aggregates confirm that they contain small amounts of $\mathrm{Ca}$. Maintaining the aqueous solution at the interface supersaturated with respect to celestite becomes progressively more difficult as the transformed layer that surrounds the unreacted gypsum core is thicker and the transfer of $\mathrm{Sr}^{2+}$ ions from the bulk solution requires a longer time. Growth under lower supersaturation could explain the celestite morphological transition from sheaf-like and spherulitic aggregates to small elongated crystals that marks the boundary between Regions 3 and 4 in celestite pseudomorphs after gypsum. It has been demonstrated that high supersaturation kinetically promotes isomorphic ion incorporation above the thermodynamic equilibrium [35]. It is worthwhile to note that the Ca content of celestite crystals in the latter region is below the EDX analysis detection limit, this is, they are basically pure celestite and their habit show characteristics that resemble those of pure celestite crystals grown in a system where mass transfer is mainly control by diffusion [34].

Though smaller than the molar volume change involved in the transformation of gypsum into celestite, a large negative molar volume change is also involved in the transformation of gypsum into barite. This means that the pseudomorphic replacement of gypsum by barite must be accompanied by the generation of a large volume of porosity. This porosity should facilitate the progress of this replacement at a rate similar to that of the replacement of gypsum by celestite. Surprisingly, this is not so. The facts that (i) the interaction of gypsum crystals with $0.5 \mathrm{M}$ Ba-bearing aqueous solutions only leads to the replacement by barite on a thin most external layer and, (ii) this layer forms shortly after the beginning of the interaction, indicate that the gypsum crystal surface rapidly becomes passivated. This passivation prevents that the gypsum dissolution-barite precipitation feedback loop can effectively operate. Based on SEM imaging observations and 2D-XRD analysis results Ruiz-Agudo et al. [36] 
recently attributed this passivation to the formation of a thin layer of epitactic barite on the gypsum surface. Indeed, there are numerous examples of mineral surface passivation by epitactic overgrowths of a secondary phase $[18,26,37,38]$. However, this passivation commonly is only partial and only leads to the slowdown of the ICDP reaction. This occurs, for example, during the interaction between anhydrite and a Ca-bearing aqueous solution [21]. Although calcite $\left(\mathrm{CaCO}_{3}\right)$ crystals grow oriented on anhydrite surfaces, the existence of epitactic relationships between both phases do not prevent the formation of fully transformed pseudomorphs of calcite after anhydrite [21]. A similar behaviour is observed during the interaction of anhydrite with Pb-bearing aqueous solutions, which leads to the formation of epitactic anglesite $\left(\mathrm{PbSO}_{4}\right)$ layers on the surface of anhydrite [24]. In these two examples the epitaxy involves phases that are not isostructural but share some common structural features. The misfit through the interface between the structures of the primary and secondary phases determines that the epitactic growth on the latter on the former takes place through a Volmer-Weber mechanism $[39,40]$. This mechanism involves the formation of oriented 3D nuclei that grow to coalesce and form an epitactic layer. This layer can completely carpet the surface of the substrate. However, because the substrate commonly contains symmetry operators, there are several equally probable symmetry related orientations for the epitactic 3D nuclei. When differently oriented 3D nuclei coalesce, they leave micropores between crystal grains. Consequently, the so-formed epitactic layers contain a certain amount of microporosity and are unable to completely armour the substrate from interaction with an aqueous solution $[21,24,26]$. Only when the primary and secondary phases involved in an ICDP reaction are isostructural and have similar lattice parameters the formation of an epitactic overgrowth can lead to the complete stoppage of the ICDP reaction. This has been observed, for example, during the interaction of calcite $\{10 \overline{1} 4\}$ surfaces with Cd-bearing aqueous solutions [37]. In this case, this interaction leads to the rapid formation of a nanometric epitactic layer of isostructural otavite $\left(\mathrm{CdCO}_{3}\right)$ on the calcite surface. The almost perfect match between the structures of calcite and otavite through the interface facilitates that the epitactic growth takes place through a Frank van der Merwe or a Stranski-Krastanov epitactic mechanism [41-43]. These mechanisms involve the growth and coalescence of epitactic 2D nuclei and the perfect substrate armouring that the so-formed epitactic layer explains the extremely low ability of calcite surfaces to remove $\mathrm{Cd}^{2+}$ ions form aqueous solutions through coprecipitation processes.

Barite and gypsum are not isostructural. Furthermore, the epitactic relationships between barite and gypsum reported by Ruiz-Agudo et al. [36] involve the parallelism of $(010)_{\mathrm{Gp}}$ and $\{001\}_{\text {Brt }}$ planes and only one crystallographic direction contained within these planes ([100]Gp || [010]Brt). Despite the low mismatch $(-3.8 \%)$ between [100]Gp and [010]Brt, it is very unlikely that a complete substrate armouring could result from the formation of an uni-directional epitactic layer. Interestingly, despite celestite and anglesite being isostructural with gypsum, these phases grow randomly oriented on gypsum $(010)$ substrates $[39,44]$. Moreover, as explained in the Results section, our SEM observations do not clearly support an epitactic growth of barite on gypsum surfaces. Indeed, most barite crystals (Figure 7) appear with their large face (001) laying approximately parallel to the gypsum (010) form. However, numerous barite crystals show other orientations. More importantly, not all barite crystals that lay with their (001) plane parallel to $(010)_{\mathrm{Gp}}$ are equally oriented but many appear differently rotated with respect to their [001] direction. This crystal arrangement could be the result of barite crystals forming in the layer of aqueous solution closest to the gypsum (010) surface through a homogeneous nucleation mechanism and the settling by gravity on the gypsum surface. Because these barite crystals are extremely platy, this settling mechanism would lead to most of them laying with their most developed face parallel to the gypsum substrate surface. Furthermore, this settling mechanism would also account for the dispersion in the rotation of these crystals around their [001] axis. It is important to take into account that barite is very sparingly soluble and as soon as gypsum starts to dissolve in contact with a $0.5 \mathrm{M}$ Ba-bearing aqueous solution, the supersaturation with respect to barite of the solution layer immediately in contact with the gypsum surface will be extremely high. This can make it possible that the barrier for barite homogeneous nucleation is overcome and barite nuclei 
form in this solution layer. It is also worthwhile to note that the morphology of the barite crystals that constitute the transformed rim around the unreacted gypsum crystal closely resemble the habit of barite crystals that precipitate by rapidly mixing aqueous solutions [45]. In such a system barite nucleation is homogeneous and takes place under very high supersaturation conditions. The proposed crystal settling mechanism would lead to the formation of a transformed layer that could contain a certain degree of porosity. However, a large porosity volume alone does not guarantee an effective pathway for mass transfer from the bulk solution to the primary phase-secondary phase interface. Interconnection and tortuosity are main properties which play a more important role than porosity volume in defining mass transfer rates through porosity networks. The interconnection of a porous network that results from the parallel stacking of platy crystals will be low while its tortuosity will be high. Consequently, regardless of what the origin of the arrangement of barite crystals in the transformed layer around the unreacted gypsum crystal could be, epitactic growth or settling by gravity, the morphology of these barite crystals arises as a critical factor that contributes to completely armor the gypsum substrate and leads to the stoppage of the interface coupled gypsum dissolution-barite crystallization reaction.

It is well known that most of the largest deposits of celestite in the world are associated to the evaporate-carbonate environment realm [3]. Although a genetic relationship between these deposits and massive precipitation during the early stages of evaporation of seawater was early proposed [46,47], this hypothesis was soon discarded since it was not supported by experimental or field observations [3]. Most authors support hypotheses that connect the formation of celestite massive deposits to processes that take place during burial diagenesis $[3,6,48,49]$. These processes would involve the interaction of carbonates and calcium sulfates with basinal fluids that have anomaly high $\mathrm{Sr} / \mathrm{Ba}$ ratios after undergoing $\mathrm{Sr}$ enrichment due to (i) the diagenetic alteration of Sr-rich carbonates, that releases Sr to the basinal fluid and (ii) continuous barite precipitation, which removes Ba from the basinal fluid $[3,6]$. The results of our study support that the interaction of a calcium sulfate phase, like gypsum, with a Ba-bearing aqueous solution results in the rapid precipitation of barite. However, it is unlikely that this interaction can lead to the formation of barite massive deposits through the replacement of calcium sulfates, as gypsum surfaces become rapidly passivated due to barite precipitation. Due to the large difference between the solubility products of the endmembers of the barite-celestite solid solution, precipitates that result from the interaction of fluids with an extremely wide range of $\mathrm{Ba} / \mathrm{Sr}$ ratios with calcium sulfate evaporites will be almost pure barite $[3,6,50,51]$. Consequently, this interaction is likely to be a mechanism for the progressive $\mathrm{Sr}$-enrichment of basinal fluids to $\mathrm{Sr} / \mathrm{Ba}$ ratios that allow for the formation of celestite. Our results demonstrate that, if gypsum crystals are in contact with a Sr-rich fluid, they can be rapidly replaced by celestite through an ICDP reaction. The fast kinetics of this replacement reaction and the fact it results in local rather that disperse precipitation of celestite gives credit to the replacement of calcium sulfates by celestite hypothesis to explain the genesis of massive celestite deposits in sedimentary basins.

\section{Conclusions}

This study shows that the interaction of gypsum with a Sr-bearing aqueous solution leads to the pseudomorphic replacement of this phase through an ICDP reaction mechanism. The progress of the reaction is strongly facilitated by the generation of a high volume of porosity that balances the negative molar volume change involved in the gypsum to celestite transformation. This porosity communicates the Sr-bearing bulk solution and the interface where the reaction takes place, hence, allowing the mineral replacement process progress to completion. Interestingly, only a very thin layer of barite crystals form around gypsum crystals in contact with Ba-bearing aqueous solutions. Although the formation of this layer also is the result of an ICDP reaction, this reaction does not progress further due to the armoring of the gypsum substrate by the barite overgrowth. The morphological characteristics of barite crystals, which can be attributed to their formation under very high supersaturation conditions, as well as the spatial relationships of barite crystals between them and with respect to the gypsum substrate are key in defining the very high effectiveness of this armoring. This results highlight the 
relevance of taking into consideration the textural characteristics of replaced layers together with involved molar volume and solubility changes when studying fluid driven mineral replacement processes. Our results may also contribute to explain the oddity of evaporite sediments-associated barite deposits, which is in contrast with the relative abundance of celestite deposits hosted in evaporitic rocks and the wide distribution of barite deposits in a variety of other geological settings.

Author Contributions: P.F. performed the laboratory experiments and the DRX analyses and prepared the samples for SEM imaging and EDX analyses. All authors (P.F., J.M.A., and L.F.-D.) contributed to the conception of the study, the analysis of the data and participated in the preparation of the manuscript. All authors have read and agreed to the published version of the manuscript.

Funding: This study was supported by the Ministry of Science, Innovation and Universities (CIENCIA) (Spain) under project CGL2016-77138-C2-1-P. Pablo Forjanes acknowledges funding through contract FPU17/01689 from the Spanish CIENCIA.

Acknowledgments: The authors thank the National Centre of Electronic Microscopy (CNME) and the X-ray Diffraction Central Service of the Complutense University of Madrid for kindly providing technical support to their research.

Conflicts of Interest: The authors declare no conflict of interest.

\section{References}

1. Hanor, J.S. Frequency distribution of compositions in the barite-celestite series. Am. Miner. 1968, 53, 1215-1222.

2. Prieto, M.; Putnis, A.; Fernández-Díaz, L. Crystallization of solid solutions from aqueous solutions in a porous medium: Zoning in (Ba, Sr)SO . Geol. Mag. 1993, 130, 289-299. [CrossRef]

3. Hanor, J.S. Barite-celestine geochemistry and environments of formation. Rev. Miner. Geochem. 2000, 40, 193-275. [CrossRef]

4. Warren, J.K. Evaporites: Sediments, Resources and Hydrocarbons; Springer Science \& Business Media: Berlin, Germany, 2006.

5. Pohl, W.L. Economic Geology: Principles and Practice; John Wiley \& Sons: Hoboken, NJ, USA, 2011.

6. Hanor, J.S. A Model for the origin of large carbonate- and evaporite-hosted celestine $\left(\mathrm{SrSO}_{4}\right)$ deposits. J. Sediment. Res. 2004, 74, 168-175. [CrossRef]

7. García-Veigas, J.; Rosell, L.; Cendón, D.I.; Gibert, L.; Martín, J.M.; Ruiz, J.T.; Ortí, F. Large celestine orebodies formed by early-diagenetic replacement of gypsified stromatolites (Upper Miocene, Montevive-Escúzar deposit, Granada Basin, Spain). Ore Geol. Rev. 2015, 64, 187-199. [CrossRef]

8. Mossman, D.J.; Brown, M.J. Stratiform barite in sabkha sediments, Walton-Cheverie, Nova Scotia. Econ. Geol. 1986, 81, 2016-2021. [CrossRef]

9. Putnis, A. Mineral replacement reactions. Rev. Miner. Geochem. 2009, 70, 87-124. [CrossRef]

10. Putnis, C.V.; Fernández Díaz, L. Ion partitioning and element mobilization during mineral replacement reactions in natural and experimental systems. EMU Notes Miner. 2010, 10, 189-226.

11. Pedrosa, E.T.; Putnis, C.V.; Renard, F.; Burgos-Cara, A.; Laurich, B.; Putnis, A. Porosity generated during the fluid-mediated replacement of calcite by fluorite. CrystEngComm 2016, 18, 6867-6874. [CrossRef]

12. Putnis, A. Mineral replacement reactions: From macroscopic observations to microscopic mechanisms. Miner. Mag. 2002, 66, 689-708. [CrossRef]

13. Ruiz-Agudo, E.; Putnis, C.V.; Putnis, A. Coupled dissolution and precipitation at mineral-fluid interfaces. Chem. Geol. 2014, 383, 132-146. [CrossRef]

14. Pollok, K.; Putnis, C.V.; Putnis, A. Mineral replacement reactions in solid solution-aqueous solution systems: Volume changes, reactions paths and end-points using the example of model salt systems. Am. J. Sci. 2011, 311, 211-236. [CrossRef]

15. Perdikouri, C.; Kasioptas, A.; Geisler, T.; Schmidt, B.C.; Putnis, A. Experimental study of the aragonite to calcite transition in aqueous solution. Geochim. Cosmochim. Acta 2011, 75, 6211-6224. [CrossRef]

16. Casella, L.A.; Griesshaber, E.; Yin, X.; Ziegler, A.; Mavromatis, V.; Müller, D.; Ritter, A.-C.; Hippler, D.; Harper, E.M.; Dietzel, M.; et al. Experimental diagenesis: Insights into aragonite to calcite transformation of Arctica islandica shells by hydrothermal treatment. Biogeosciences 2017, 14, 1461-1492. [CrossRef] 
17. Lafay, R.; Montes-Hernandez, G.; Renard, F.; Vonlanthen, P. Intracrystalline reaction-induced cracking in olivine evidenced by hydration and carbonation experiments. Minerals 2018, 8, 412. [CrossRef]

18. Putnis, C.V.; Tsukamoto, K.; Nishimura, Y. Direct observations of pseudomorphism: Compositional and textural evolution at a fluid-solid interface. Am. Miner. 2005, 90, 1909-1912. [CrossRef]

19. Prieto, M.; Cubillas, P.; Fernández-González, A. Uptake of dissolved Cd by biogenic and abiogenic aragonite: A comparison with sorption onto calcite. Geochim. Cosmochim. Acta 2003, 67, 3859-3869. [CrossRef]

20. Pedrosa, E.T.; Boeck, L.; Putnis, A. The replacement of a carbonate rock by fluorite: Kinetics and microstructure. Am. Miner. 2017, 102, 126-134. [CrossRef]

21. Roncal-Herrero, T.; Astilleros, J.M.; Bots, P.; Rodríguez-Blanco, J.D.; Prieto, M.; Benning, L.G.; Fernández-Díaz, L. Reaction pathways and textural aspects of the replacement of anhydrite by calcite at $25^{\circ} \mathrm{C}$. Am. Miner. 2017, 102, 1270-1278. [CrossRef]

22. Xia, F.; Brugger, J.; Chen, G.; Ngothai, Y.; O’Neill, B.; Putnis, A.; Pring, A. Mechanism and kinetics of pseudomorphic mineral replacement reactions: A case study of the replacement of pentlandite by violarite. Geochim. Cosmochim. Acta 2009, 73, 1945-1969. [CrossRef]

23. Xia, F.; Brugger, J.; Ngothai, Y.; O’Neill, B.; Chen, G.; Pring, A. Three-Dimensional ordered arrays of zeolite nanocrystals with uniform size and orientation by a pseudomorphic coupled dissolution-reprecipitation replacement route. Cryst. Growth Des. 2009, 9, 4902-4906. [CrossRef]

24. Morales, J.; Astilleros, J.M.; Fernández-Díaz, L.; Álvarez-Lloret, P.; Jimenez, A. Anglesite $\left(\mathrm{PbSO}_{4}\right)$ epitactic overgrowths and substrate-induced twinning on anhydrite $\left(\mathrm{CaSO}_{4}\right)$ cleavage surfaces. J. Cryst. Growth 2013, 380, 130-137. [CrossRef]

25. Qian, G.; Li, Y.; Gerson, A.R. Applications of surface analytical techniques in Earth Sciences. Surf. Sci. Rep. 2015, 70, 86-133. [CrossRef]

26. Cuesta-Mayorga, I.; Astilleros, J.M.; Fernández-Díaz, L.; Morales, J.; Prieto, M.; Roncal-Herrero, T.; Benning, L.G. Epitactic overgrowths of calcite $\left(\mathrm{CaCO}_{3}\right)$ on anhydrite $\left(\mathrm{CaSO}_{4}\right)$ cleavage surfaces. Cryst. Growth Des. 2018, 18, 1666-1675. [CrossRef]

27. Fernández-Díaz, L.; Pina, C.M.; Astilleros, J.M.; Sánchez-Pastor, N. The carbonatation of gypsum: Pathways and pseudomorph formation. Am. Miner. 2009, 94, 1223-1234. [CrossRef]

28. Jonas, L.; John, T.; King, H.; Geisler, T.; Putnis, A. The role of grain boundaries and transient porosity in rocks as fluid pathways for reaction front propagation. Earth Planet. Sci. Lett. 2014, 386, 64-74. [CrossRef]

29. Greiner, M.; Fernández-Díaz, L.; Griesshaber, E.; Zenkert, M.N.; Yin, X.; Ziegler, A.; Veintemillas-Verdaguer, S.; Schmahl, W.W. Biomineral Reactivity: The Kinetics of the Replacement Reaction of Biological Aragonite to Apatite. Minerals 2018, 8, 315. [CrossRef]

30. Kostov, I.; Kostov, R.I. Crystal Habits of Minerals; Drinov Acedemic Publishing House \& Pensoft Publishers: Sofia, Bulgaria, 1999.

31. Dinnebier, R.E.; Billinge, S.J.L. Principles of powder diffraction. In Powder Diffraction Theory and Practice; RSC Publishing: Cambridge, UK, 2008.

32. Zhao, J.; Brugger, J.; Grundler, P.V.; Xia, F.; Chen, G.; Pring, A. Mechanism and kinetics of a mineral transformation under hydrothermal conditions: Calaverite to metallic gold. Am. Miner. 2009, 94, 1541-1555. [CrossRef]

33. Pöml, P.; Menneken, M.; Stephan, T.; Niedermeier, D.R.D.; Geisler, T.; Putnis, A. Mechanism of hydrothermal alteration of natural self-irradiated and synthetic crystalline titanate-based pyrochlore. Geochim. Cosmochim. Acta 2007, 71, 3311-3322. [CrossRef]

34. Sánchez-Pastor, N.; Pina, C.; Fernández-Díaz, L. Relationships between crystal morphology and composition in the $(\mathrm{Ba}, \mathrm{Sr}) \mathrm{SO}_{4}-\mathrm{H}_{2} \mathrm{O}$ solid solution-aqueous solution system. Chem. Geol. 2006, 225, 266-277. [CrossRef]

35. Putnis, A.; Prieto, M.; Stoll, H. Effects of kinetics and mechanisms of crystal growth on ion-partitioning in solid solution-aqueous solution (SS-AS) systems. EMU Notes Miner. 2010, 10, 43-64.

36. Ruiz-Agudo, C.; Álvarez-Lloret, P.; Di Lorenzo, F.; Gebauer, D.; Putnis, C.V. Baryte cohesive layers formed on a (010) gypsum surface by a pseudomorphic replacement. Eur. J. Miner. 2019, 31, 289-299. [CrossRef]

37. Pérez-Garrido, C.; Fernández-Díaz, L.; Pina, C.M.; Prieto, M. In situ AFM observations of the interaction between calcite $\{10 \overline{1} 4\}$ surfaces and Cd-bearing aqueous solutions. Surf. Sci. Rep. 2007, 601, 5499-5509. [CrossRef] 
38. Pérez-Garrido, C.; Astilleros, J.M.; Fernández-Díaz, L.; Prieto, M. In situ AFM study of the interaction between calcite $\{10 \overline{1} 4\}$ surfaces and supersaturated $\mathrm{Mn}^{2+}-\mathrm{CO}_{3}{ }^{2-}$ aqueous solutions. J. Cryst. Growth 2009, 311, 4730-4739. [CrossRef]

39. Copel, M.; Reuter, M.C.; Kaxiras, E.; Tromp, R.M. Surfactants in epitaxial growth. Phys. Rev. Lett. 1989, 63, 632-635. [CrossRef]

40. Evans, M.M.R.; Glueckstein, J.C.; Nogami, J. Epitaxial growth of manganese on silicon: Volmer-Weber growth on the Si(111) surface. Phys. Rev. B 1996, 53, 4000-4004. [CrossRef]

41. Van Der Merwe, J.H. Equilibrium Structure of a Thin Epitaxial Film. J. Appl. Phys. 1970, 41, 4725-4731. [CrossRef]

42. Van Der Merwe, J.H. Structure of epitaxial crystal interfaces. Surf. Sci. Rep. 1972, 31, 198-228. [CrossRef]

43. Van Der Merwe, J.H. Analytical selection of ideal epitaxial configurations and some speculations on the occurrence of epitaxy I. Epitaxy with rectangular interfacial atomic meshes. Philos. Mag. 1982, 45, 127-143. [CrossRef]

44. Forjanes, P.; Astilleros, J.M.; Fernández-Díaz, L. Role of epitactic relationships in the replacement of anhydrite $\left(\mathrm{CaSO}_{4}\right)$ by celestite $\left(\mathrm{SrSO}_{4}\right)$. Geophys. Res. Abstr. EGU Gen. Assembly 2019, 21, 16150.

45. Fernández-Díaz, L.; Putnis, A.; Cumberbatch, T.J. Barite nucleation kinetics and the effect of additives. Eur. J. Miner. 1990, 2, 495-502. [CrossRef]

46. Müller, G. Zür Geochemie des Strontiums in Ozeanen Evaporiten unter besonderer Berücksichtigung der sedimentären Coelestinlagerstätten von Hemmelte-West (Süd-Oldenburg); Akademie Verlag Berlin: Berlin, Germany, 1962.

47. Brodtkorb, M.K.; Ramos, V.; Barbieri, M.; Ametrano, S. The evaporitic celestite-barite deposits of Neuquen, Argentina. Miner. Depos. 1982, 17, 423-436. [CrossRef]

48. Carlson, E.H. Celestite replacements of evaporates. Sed. Geol. 1987, 54, 93-112. [CrossRef]

49. Scholle, P.A.; Stemmerik, L.; Harpoth, O. Origin of major karst-associated celestine mineralization in Karstrynggen, Central East Greenland. J. Sed. Pet. 1990, 60, 397-410.

50. Prieto, M.; Fernández-González, A.; Putnis, A.; Fernández-Díaz, L. Nucleation, growth, and zoning phenomena in crystallizing $(\mathrm{Ba}, \mathrm{Sr}) \mathrm{CO}_{3}, \mathrm{Ba}\left(\mathrm{SO}_{4}, \mathrm{CrO}_{4}\right),(\mathrm{Ba}, \mathrm{Sr}) \mathrm{SO}_{4}$, and $(\mathrm{Cd}, \mathrm{Ca}) \mathrm{CO}_{3}$ solid solutions from aqueous solutions. Geochim. Cosmochim. Acta 1997, 61, 3383-3397. [CrossRef]

51. Prieto, M. Thermodynamics of solid solution-aqueous solution systems. Rev. Miner. Geochem. 2009, 70, 47-85. [CrossRef] 